Chapter 14

\title{
DIGITAL SOIL MAPPING AT A NATIONAL SCALE: A KNOWLEDGE AND GIS BASED APPROACH TO IMPROVING PARENT MATERIAL AND PROPERTY INFORMATION
}

\author{
R. Lawley and B. Smith
}

\begin{abstract}
One of the fundamental parameters in the soil formation equation is that relating to the parent material from which the soils have been derived. Such information is typically derived from geological surveys and paper maps. However, an increasing propensity to directly produce digital geological maps and associated data bases means that a far greater range of information can be made available to assist the soil scientist in mapping and predicting soil characteristics. Such geo-information typically can include, detailed lithological parameters, geochemistry of soils and sediments, engineering parameters and remotely sensed information.

In this paper we describe on-going work at the British Geological Survey in which we are actively developing a national digital parent material map and property data base at a scale of 1:50 000. The main aim in doing this is to support the development of national soil data sets at a similar scale by those responsible for soil survey in the UK. However, our experience to date suggests that an adoption of similar strategies in regions and countries with sparse, soil orientated, data infrastructures could be of considerable value. For example many countries have, or are receiving, aid in support of the development and licensing of mineral resources (i.e. Madagascar, Afghanistan and Mauritania) which include not only significant improvements in geological mapping and associated GIS infrastructure, but also remote sensing and geochemical survey.
\end{abstract}

\subsection{Introduction}

In 2005 the British Geological Survey (BGS) began a five-year programme of research entitled 'sustainable soil management'. The aim of the programme is to produce an integrated analysis of the UK's near surface environment by developing (a) improved soil-parent material maps at 1:50 000 scale, (b) 3-D modelling capability of the near surface environment (see Chapter 16) and (c) increased knowledge of processes that occur within this near surface zone.

Drivers for funding this new work programme included an increasing scientific (Anderson et al, 2004; Zanner and Graham, 2005 and Wysocki et al, 2005) and legislative interest (DEFRA, 2004) in the characteristics of the near surface (the region typically less than $5 \mathrm{~m}$ below ground level). In undertaking this programme of activities BGS also hoped to be in a position to assist the UK soil-science community in meeting the needs of emerging soil policies that are based on the assessment of soil function.

In the UK it has been recognised that whilst the 1:250 000 scale soil maps (Mackney et al., 1983) offer full national coverage of soil information, there is also a need for similar data at 1:50 000 scale. This is required to support increasingly integrated European framework directives, England's soil action plan (DEFRA, 2004) and for managing the impact of climate change of soil resources. Unfortunately soil data at this scale is not systematically available in the UK (or indeed in many other countries). These factors together with the completion of the UK digital geological map at a scale of 1:50 000 and the implementation of a policy to digital archive all legacy geo-data at BGS (Jackson and Green, 2003) provided the catalyst for producing an improved soil-parent material map (see Figure 14.1) as part of the BGS sustainable soil management programme. 
As a result of the digitisation of legacy data, and publication of a digital geological map for the whole of the UK (solid and drift) it is now possible to offer a multitude of datasets and models, rather than 'just' the traditional single-purpose geology map. It is also possible for the first time to interactively trace the source information back to scanned archive material. However, in making digital maps geologists have had to discard traditional cartographic production values, and move toward more 'mechanistic' map data. Like soil maps, geological maps are a synthesis of empirical knowledge; the subtleties and detail of the rocks, traditionally shown by cartographic elegance of shading, or spatially unconstrained comments on the map face, are often lost once the map is digitised and made available through GIS. When that data is subsequently used by non-geologists or reprocessed by rulebased GIS systems to make derivative maps, the geological data often becomes problematic with a tendency towards overly complex or poorly defined classifications.

\section{$<$ Plate 14.1 near here $>$}

The Parent Material Map (PMM) shown in Plate 14, is an attempt by BGS to remove the complexity of geology description as detailed in the BGS lexicon of named rock units (BGS, 2006) from its baseline datasets and at the same time re-introduce spatial data previously unpublished because it was regarded as 'outside the remit' of the national geological survey.

Once completed, it is intended that the PMM will become a fundamental baseline dataset for soil scientists to use in the creation of their own soil models for the UK (potentially via the scorpan variables as described by McBratney et al., 2003) where data relating to climate, land use, relief and parent material is available at similar, or better scales.

For the past decade a significant amount of World Bank funding has been focussed on the upgrading of geological mapping via digital methodologies, remote sensing and geochemical survey in response to mineral exploration and mining sector development. We propose that methodologies BGS have employed in the development of the UK PMM, together with the existence of upgraded information from the mining sector provide an opportunity for the production of digital parent material maps and associated databases. These digital maps in turn could represent a first, but significant step in closing the information gap, which hinders the development of digital soil models in countries with poor or non-existent data infrastructure.

\subsection{Methodologies, Results and Discussion}

The Parent Material Map derives its core spatial framework and descriptive content from main BGS dataset: DigMapGB50 (BGS, 2005). DigmapGB50 is a typical lithostratigraphical geology map and dataset. It has been derived from empirical methods of geological survey over many years, at scales of between 1:10 000 and 1:25 000, with cartographic generalisation for final publication at 1:50 000 scale. Like all geological maps there is reliance upon the skills and ability of the surveyor to 'interpret' landscape, soils and outcrop to create the map. However, map quality is ultimately constrained by cost, complexity and survey objectives. In the UK (and in many international surveys) geological maps exhibit four common flaws:

1. A tendency to concentrate on hard rock (bedrock) geology or economic geology, at the expense of superficial (near-surface) deposits or un-economic strata. 
2. A tendency for lithological descriptions to concentrate on 'fresh' material characteristics, with only brief descriptions of weathered material. (Soil information can rarely, if ever, be found on a published geological map).

3. A lack of freely accessible, quantified analysis and description of the rocks and associated properties

4. Highly clustered sample and survey patterns (databases are a 'patchwork quilt' of information rather than a seamless entity)

As a result of these flaws, some geological maps do not necessarily define what immediately lies beneath the soil and thus they can make poor parent-material maps. However, mining the archive datasets and reconstructing the geological map with an emphasis on near surface materials makes it is possible to correct these issues. For example, in the production of our UK PMM we aim to (1) use data mining and terrain modelling to spatially delineate unpublished surficial deposits, and (2) reattribute and simplify geological terminology to make data contained within the geological map more useful to potential users as a parent material map. In the longer term we also aim to incorporate information from:

1. The statistical integration of geochemical, engineering and other quantified survey information

2. The integration of remotely sensed data. For example DTMs, Spectral Gamma, Landsat, SRTM, ASTER, GPR etc.

3. The integration of 'traditional' soil survey and profile data (if available at similar scales, for improving and testing the simplification process on a regional basis)

4. Confidence mapping of the PMM

These short and longer terms aims are discussed in more detail below.

\subsubsection{Data mining for unpublished surficial deposits}

$<$ Fig 14.1 near here >

In the UK, geology maps are traditionally divided into two groups: Bedrock and Superficial. Bedrock mapping delineates rocks more than $\sim 2.6$ million years old, Superficial mapping delineates deposits less than 2.6 million years old (also termed 'Quaternary' deposits). For much of BGS' 170-year history, bedrock mapping in the UK was driven primarily by a need to find mineral and coal resources. It has only been in the last 40 or so years that Quaternary and non-economic deposits have been surveyed as 'primary targets' for research. The Quaternary history of the UK comprises a cyclical succession of ice advance and retreat, the most recent of which, known as the 'Devensian', began 80 000 years BP and ended 10000 years BP . During the latest stages of the cold period, northern UK was buried under glaciers and ice fields, whilst southern UK was subject to periglacial conditions. The Quaternary geology of the UK is a complex system of ice contact, outwash and soliflucted deposits. These deposits present specific difficulties for geological survey; they are generally heterolithic and spatially complex. Previous attempts to use geology maps for soil modelling (Mayr et al, 2001) have indicated that the geological map for the UK under-represents Quaternary and Holocene (recent) deposits at surface, and that three specific deposits form the bulk of the missing deposits: Peat, Colluvium and Loess (including coversand). These deposits exhibit blanket-like forms and where present are generally less than 1 or $2 \mathrm{~m}$ thick. Typically, these deposits have been observed during the early surveys and commonly their 
presence has been 'indicated' with map-face annotation, but not necessarily identified via a specific map boundary. As a result, a lot of field-based evidence within these legacy records is 'unpublished' and missing from the modern digital output. These unpublished data can be partly 'restored' to the PMM by undertaking an extensive data rescue and renewal process to seek out and digitally capture them (see Chapter 6) .

Additionally, Peat, Loess and coversands have been exploited as resources in the UK and so some sparse sample information is available from BGS national and regional surveys for resources. Where archive searches fail, remote-sensing techniques can assist. Several satellite and airborne sensors provide spectra suitable for deriving pseudo-maps of Peat distribution, as well as Aerial photo interpretations. However, Colluvium presents a problem in that its heterolithic composition and ubiquitous and complex habit make accurate and consistent survey difficult. Descriptions of this soliflucted material are often deliberately 'vague', and in areas of Till deposits, delineation of Colluvium is extremely difficult. To resolve the possible extent of this deposit, we are using terrain analysis to determine areas where such deposits may have accumulated over time and analysis of 'upslope areas' for these locations to determine potential lithological characteristics (see Figure 14.2).

$<$ Fig 14.2 near here $>$

\subsubsection{Re-attribution and simplification of geological terminology}

The reattribution and simplification of geological terminology is crucial to the success of the PMM. This is to allow a wider audience to easily use the dataset without having to become too geologically aware or spend resources on lengthy 'background' research. There are two reasons why this is a critical issue for BGS. Firstly, fewer environmental-science students are gaining the geological training needed to understand traditional geological datasets. Secondly, the creation of near-surface and soils data is increasingly computer-based (specifically GIS) and for best results, computer models require simple binary rules for quantifying variables. Finally the number of geological units described in the BGS Lexicon, and mapped in the UK's 1:50 000 digital geological map has increased to over 9000 . This compares to the 26 parent material classifications used in the UK's national scale 1:250 000 soil mapping programme (Mackney et al, 1983). It is important; therefore, that we deliver a balanced level of attribute information that integrates with other users needs in a form that is optimised for computer manipulation.

Simplification of attributes for the PMM begins with the standard lithological description of the rock/deposits. All the deposits shown on the UK geology map are re-described using a hierarchical rock classification scheme developed by BGS (Gillespie and Styles, 1999). The user can thus 'step back' from the detailed description through the hierarchy, to a simpler root description. i.e. Troctolite can be reattributed as gabbroic rock, coarse crystalline igneous basic rock, igneous basic rock, or simply, igneous rock. At the same time, detailed information that is considered implicit in geology descriptions (i.e., texture or mineralogy) can be made more explicit for other users.

In its current version the PMM offers a series of relatively simple semi-qualitative attributes for each mapped deposit. These include: texture, colouration, mineralogy (including specific minerals of importance to soil properties), porosity, permeability, strength, density, carbon content, hardness and weathering structure. The range of attribution and quantified data 
within the PMM will increase over time as more BGS and external datasets are trawled for contributing information.

\subsubsection{Integrating other data into the PMM}

Most geological survey projects incorporate an element of geochemical and engineering sampling (as well as survey specific sampling). Geochemical surveys can be stream sediment or soil sample based, and whilst designed to expose mineral/chemical properties, they will invariably describe some soil and weathered-zone characteristics and so can be used to improve the geological map. Engineering surveys typically target weathered material as part of their remit as well as unweathered rock. Either dataset offers potential for soil scientists trying to find quantified parent material characteristics. Typically the data will be site specific (i.e. a single point in 3d space) and will require cautious application and/or extrapolation to the extents of available spatial geological data. However, basic information of texture, discontinuities colour, dominant mineralogy and bulk chemistry can all potentially serve as co-variables to assist in confirming/improving the more qualitative geological map classification. Satellite and airborne sensors have played fundamental roles in geological surveys, particularly in areas of limited vegetation cover, standard scenes of Landsat 7, ASTER are being used to improve the PMM. Airborne Hyperspectral and radiometric surveys are becoming more widely used in mineral surveys, these tools offer equally good opportunities for soil scientists to derive soil characteristics (see §2.2.1). These sensors will be tested in the UK to assess their integration with the PMM to determine soil mineralogy and possibly moisture content.

\subsubsection{Confidence mapping for the PMM}

The PMM will evolve in the next four years from a 'geology map' into a 'weathered zone' model. It will comprise a combination of empirical observation, quantified point data and statistical models. In order to manage, and promote the use of this data, the PMM requires metadata and 'confidence' modelling to inform the user about how reliable the information is, and the limitations of its derivation. All the input layers to the PMM carry some form of quality assessment. Initial testing of the current version of the PMM has begun with a jointresearch project involving the National Soil Research Institute in which soil scientists are testing and training the PMM by comparison with extensive soil sample datasets and soil survey archives.

\subsubsection{Application in data poor environments}

The vast majority of soil surveying, on a regional scale, was performed in Africa and the Far East during the middle of the last century. This typically used geological information for differentiation of parent material type at a scale of 1:500 000 or larger as this was simply the only spatial framework available. Since that time higher resolution, systematic data has slowly become available as a result of mineral and resource exploration culminating with an intense period of activity during the early $21^{\text {st }}$ century. These new data sources, for example in Mozambique, Morocco, Mauritania, Madagascar, Ghana and Papua New Guinea to name but a few, typically include geological survey at a scale of 1:100 000 or smaller; multielement, multimedia geochemical survey and a suite of high resolution DTM and associated remotely sensed imagery including hyper-spectral, gamma spectrometric and radar based techniques. Whilst these mineral surveys have not explicitly deployed soil surveying, and 
therefore lack the micro-scale data needed to make a traditional soil map; they potentially contain vital data of use to the digital soil modeller. The issue becomes one of demonstrating the need for, value of, and capability of transferring the knowledge from mineralogical surveys into digital soil models, as discussed in $§ 3.2$.

\subsection{Conclusions}

Parent material mapping requires an extensive reconstruction of traditional geological linework. For the UK this involves a substantial data mining exercise, and has highlighted the need for better archiving of soil and weathering related observations. It is believed that the PMM will offer soil scientist in the UK a much-improved spatial framework on which to build 1:50 000 scale soil maps. Although the UK has abundant geological (and soil) data, it is evident from the work done so far, that many geological surveys across the world are acquiring abundant parent material data, of which only a small proportion is being 'published' within the geological map. For example many countries in Africa are revising, and in many cases remapping their geology in support of a worldwide resurgence in mineral exploration. This newly acquired material is often supported by high-resolution remote sensing data (airborne and satellite digital terrain maps, hyper spectral imagery and gamma spectrometry) which when coupled with geology offers a vast amount of information to those wishing to undertake digital soil mapping. Our experience is that geologists or soil scientists could relatively easily apply the simple data mining techniques and map reconstruction being used here to any such legacy geo-data. However, to do this, data needs to become much more widely available, with simpler and clearer terminology of relevance to soil science. It also has to be recognised that some geological maps may never make perfect parent material maps.

\section{Acknowledgements}

The authors would like to acknowledge the assistance of the many BGS staff that have contributed to the development of the PMM. R. Lawley and B. Smith publish with the approval of the Director, British Geological Survey.

\section{References}

Anderson, S.P., Blum, J., Brantley, S.L., White, A.F., Chadwick, O., Chorover, J., Derry, L.A., Drever, J.I., Hering, J.G., Kirchner, J.W., Kump, L.R., Richter, D., 2004. Proposed initiative would study Earth's Weathering Engine. EoS Transactions of the American Geophysical Union 86 (28), 265-272.

British Geological Survey, 2005. Digital Geological Map of Great Britain 1:50 000 scale (DiGMapGB-50). Version 2.11. Keyworth, Nottingham. UK

British Geological Survey, 2006. The British Geological Survey Lexicon of Named Rock Units. (www.bgs.ac.uk/lexicon/lexicon_intro.html) 
DEFRA, 2004. The first soil action plan for England 2004-2006. Department for the Environment, Food and Rural Affairs, London, UK, 36pp.

Gillespie, M.R., Styles, M.T., 1999. BGS Rock Classification Scheme Volume 1. Classification of Igneous Rocks, British Geological Survey Research Report, $\left(2^{\text {nd }}\right.$ edition) RR 99-06.

Jackson, I., Green, C., 2003. DiGMapGB - The Digital Geological Map of Great Britain. Geoscientist 13(2), 4-7.

Mackney, D., Hodgson, J.M., Hollis, J.M., Staines, S.J., 1983. The 1:250 000

National Soil Map of England and Wales. Soil Survey of England and Wales, Harpenden.

Mayr, T.R., Palmer, R., Lawley, R., Fletcher, P., 2001. New Methods of Soil Mapping. Final Report: SR0120. National Soil Resources Institute, Silsoe, UK.

McBratney, A.B., Mendonça Santos, M.L., Minasny, B., 2003. On digital soil mapping. Geoderma 117, 3-52.

Wysocki, D. A., Schoeneberger, P.J., LaGarry, H.E., 2005. Soil surveys: a window to the subsurface. Geoderma 126, 167-180.

Zanner, C.W., Graham, R.C., 2005. Deep regolith: exploring the lower reaches of soil. Geoderma 126, 1-3. 
Tables, Figures and Plates

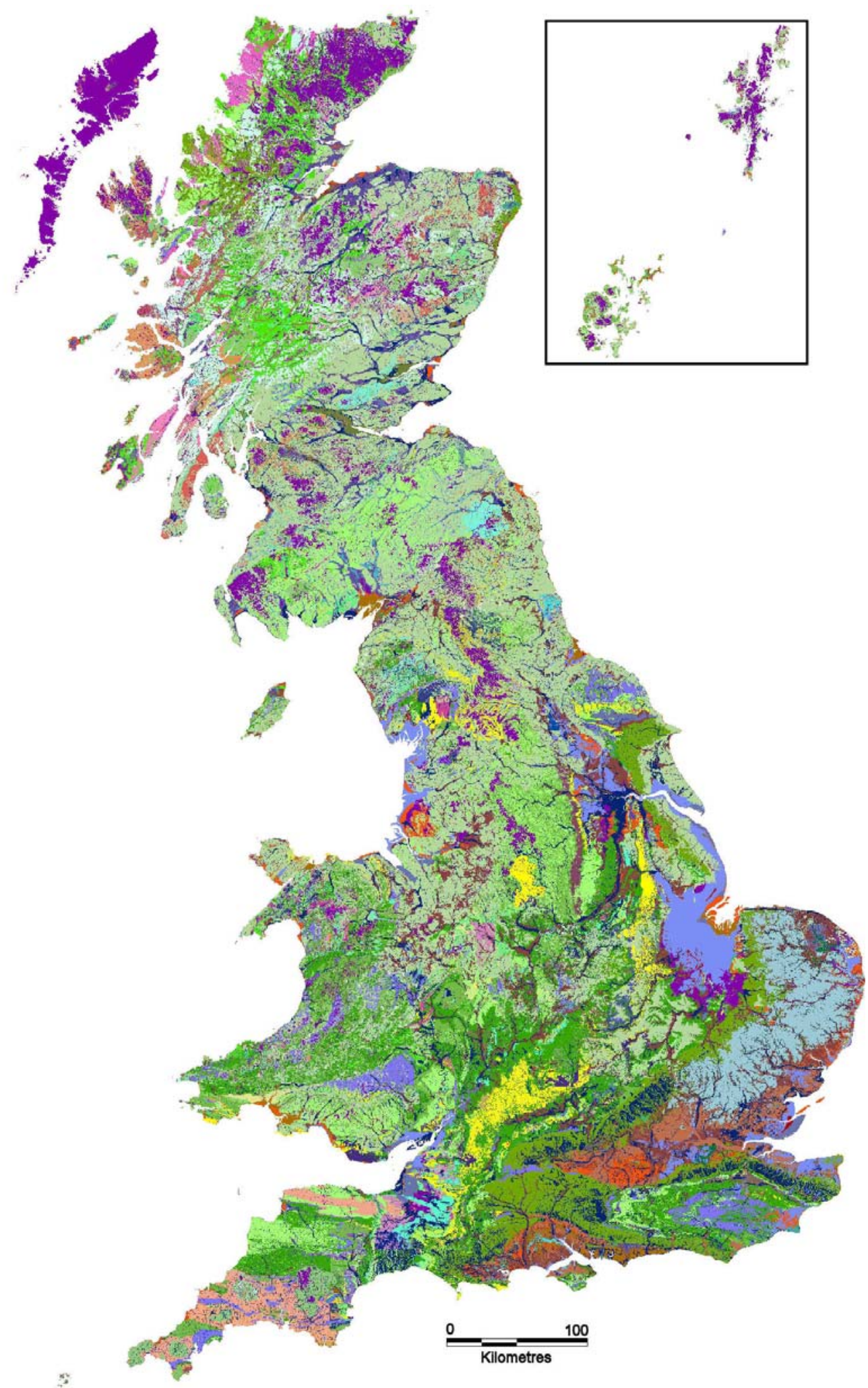

Plate 14.1 Parent Material Map for Britain (version 0.1) 


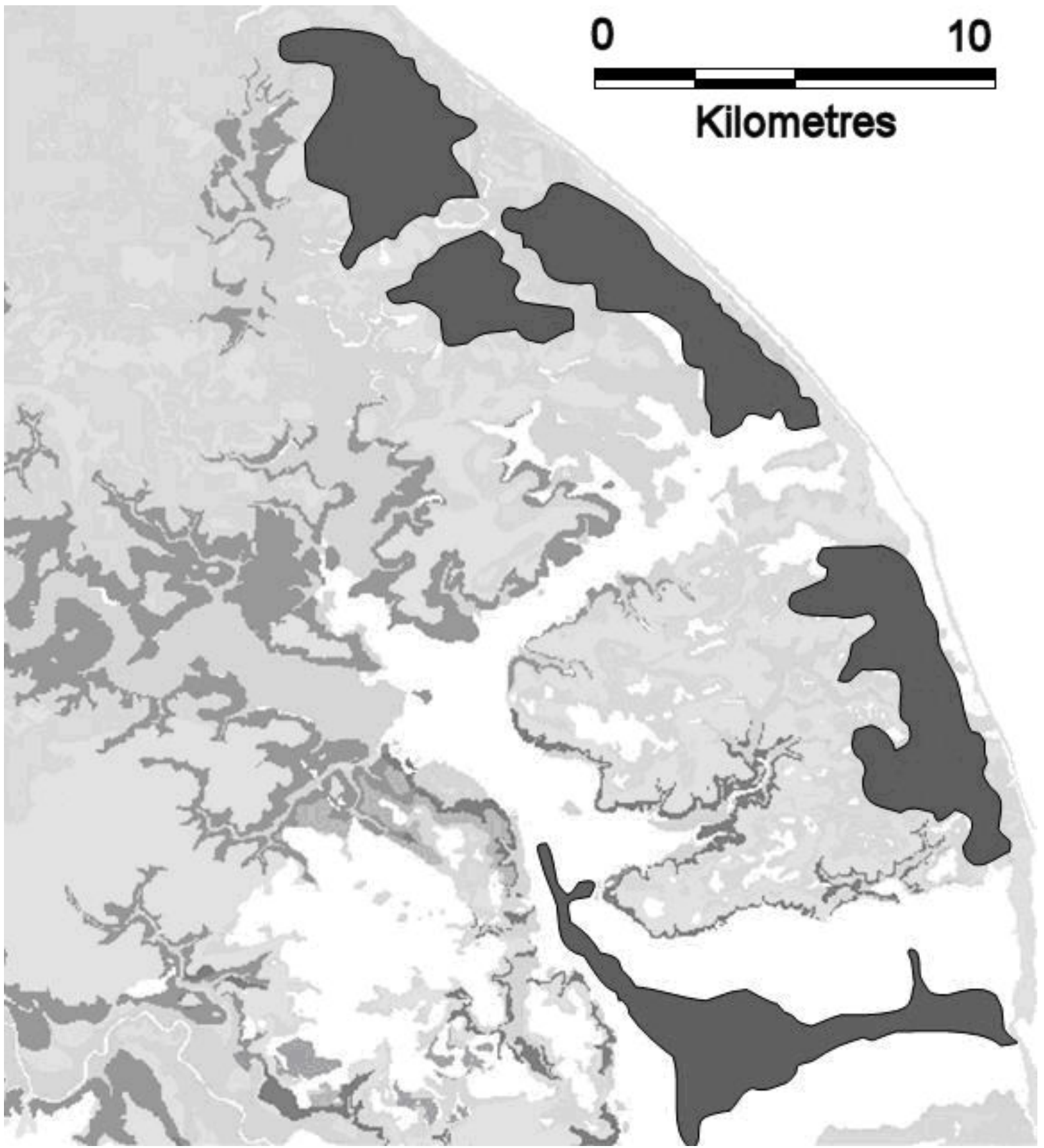

Fig. 14.1. Shows current geological map, with shaded area of unpublished loess information extracted from original fieldslips 


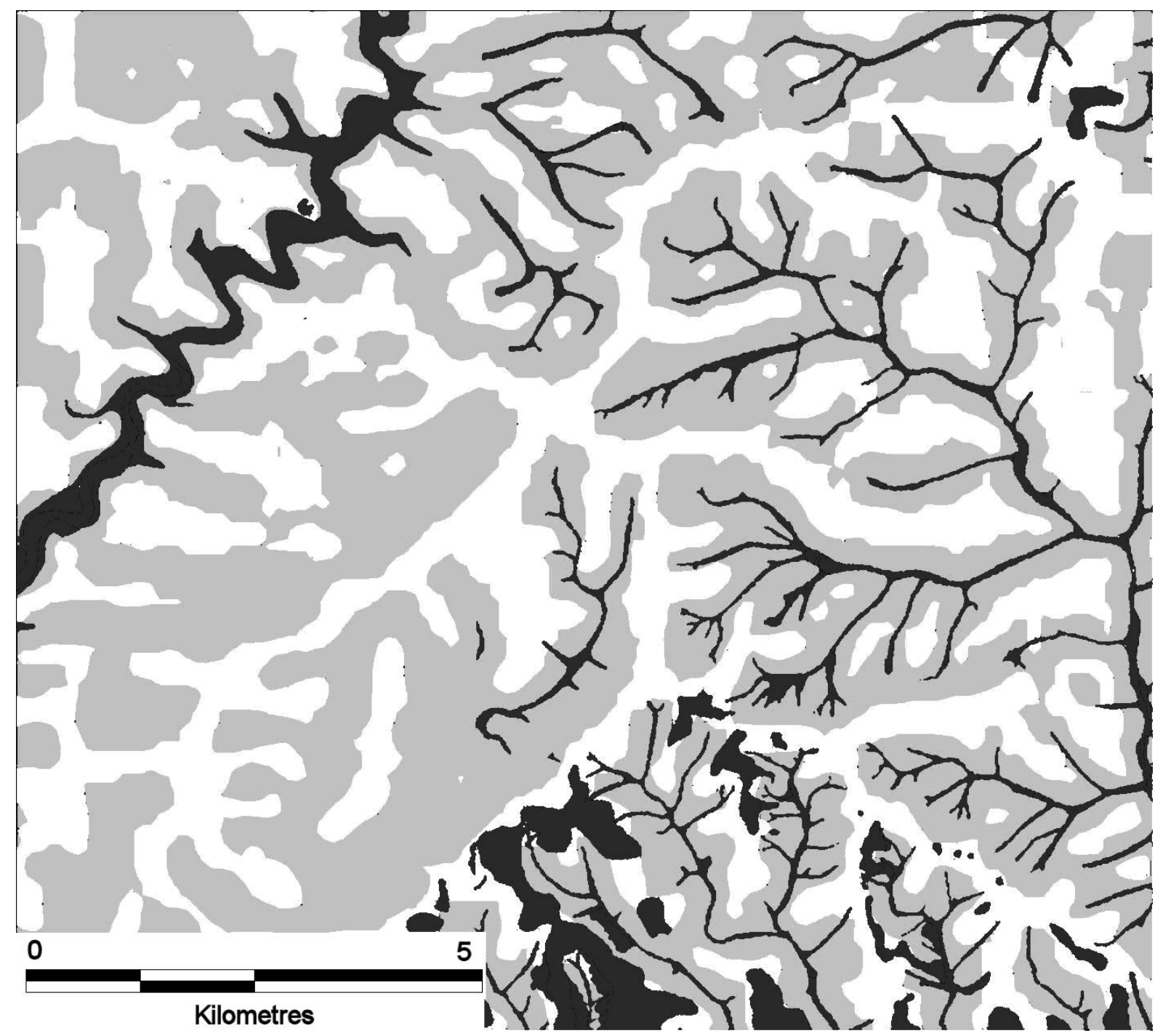

Fig. 14.2. Shows mapped superficial deposits (in dark grey colours) with modified "zones" of modelled colluvium in lighter grey. Note the absence of mapped units on the left-hand side of the image, as a result of mapping policy at time of survey. Geologists have subsequently resurveyed this area of Devizes, UK and the new survey data indicates the modelled data offers a good representation of the colluvium distribution. 


\section{Affiliations and addresses}

Lawley, R. British Geological Survey, Nottingham, NG12 5GG UK . rslaw@bgs.ac.uk Smith, B. British Geological Survey, Nottingham, NG12 5GG UK . b.smith@bgs.ac.uk

Words, phrases, terms for book index

Parent material, data mining, reinterpretation of geological nomenclature, remote sensing, ASTER, radiometric spectroscopy, confidence mapping 